\title{
ADAPTING A LABORATORY RESEARCH GROUP MODEL TO FOSTER THE SCHOLARSHIP OF TEACHING AND LEARNING
}

Beth A. Fisher, Regina F. Frey, Washington University in St. Louis

A multidisciplinary group of faculty and staff formed an education research group modeled on a laboratory research group to focus on the scholarship of teaching and learning (SoTL) in science, technology, engineering, and mathematics (STEM). This group has bridged the communication and knowledge gaps between STEM and social science faculty and science education specialists, fostered the development of collaborative SoTL projects, and laid the groundwork for broader institutional support of SoTL.

Much educational research in science, technology, engineering, and mathematics (STEM) has historically been undertaken by mathematics and science education specialists who do not typically teach undergraduate STEM courses. Recently, however, STEM faculty have become more interested in educational research and have identified participation in the scholarship of teaching and learning (SoTL) as a means of bridging the gaps that often exist between STEM faculty and specialists in mathematics and science education fields (Banchoff $\&$ Salem, 2002; Coppola \& Jacobs, 2002; Huber \& Morreale, 2002; Wankat, Felder, Smith, \& Oreovicz, 2002). As Coppola and Jacobs (2002) have argued in relation to SoTL in chemistry, faculty who teach undergraduate courses should be involved in this scholarship because "only practitioners of chemistry can recognize the common yet contentrich stumbling blocks that students face when learning chemistry" (pp. 202-203). The same argument applies to the development of SoTL in all STEM fields. 
Increasing interest in SoTL among STEM faculty can also be traced to the emphasis that major funders, including the National Science Foundation, the Howard Hughes Medical Institute (HHMI), the U.S. Department of Education, and the Institute of Education Sciences, have placed on evaluation of the programs they support (Huber \& Hutchings, 2005; Wankat et al., 2002). Such funding has enabled faculty to incorporate into their teaching innovative methods including active and collaborative learning (Coppola \& Jacobs, 2002; Wankat et al., 2002). As more STEM faculty adopt such methods, the need has developed for them to conduct evaluative studies of their own teaching and familiarize themselves with principles of human learning that are applicable to STEM classroom and laboratory teaching. Faculty developers have responded to this need with consultations and programs that provide faculty with opportunities to design teaching innovations that are informed by, and contribute to, SoTL (Sorcinelli, Austin, Eddy, \& Beach, 2006). At our university, the director of the teaching center and colleagues from across STEM disciplines developed a successful model for fostering SoTL in STEM. This Education Research Group (ERG) meets weekly in a format resembling a laboratory research group meeting. The ERG brings together a multidisciplinary group representing faculty who teach undergraduate STEM courses, faculty who conduct research in cognitive and learning sciences, and faculty and staff who develop and implement $\mathrm{K}-12$ science outreach programs.

Now in its third year, the ERG has fostered approaches to SoTL that bridge communication and knowledge gaps among groups of faculty and research staff who share a common goal of improving teaching and learning but rarely have opportunities to work together or learn from one another. The ERG has also helped to raise awareness beyond the group about the breadth of scholarship at the university and has laid the groundwork for a university center devoted to research on teaching and learning.

Although the ERG was developed in response to a specific need to evaluate in a systematic way projects funded by HHMI, it serves another, broader purpose by fostering collegial and collaborative interactions among scholars from different disciplines that the Carnegie Foundation for the Advancement of Teaching has identified as crucial to the value of SoTL (Huber $\&$ Hutchings, 2005). The group's weekly meetings define teaching and scholarship on teaching not as solitary and separate pursuits, but as mutually reinforcing work that is most productive and useful when it is undertaken within and by a community of scholars (Shulman, 1993). The ERG members share a commitment to improving 
teaching and learning in STEM and an interest in learning about and developing methods to evaluate teaching and learning. The group members' shared focus on teaching and learning in undergraduate STEM classrooms at the university means that, despite the fact that the group is multidisciplinary, their projects are grounded within discipline-specific contexts and content; this aspect of the group coheres with Lee Shulman's (1993) vision of teaching as "community property"-or work that is best developed and refined within intellectual communities that share specific disciplinary traditions.

We believe that the ERG model represents a useful response to challenges that prevail in nearly every discipline and at many colleges and universities. First, the scholarship of teaching and learning is still considered, for the most part, independent of the faculty reward structure, which traditionally focuses on faculty contributions to "the scholarship of discovery" (Boyer, 1990). Second, there is a dearth of institutional support for SoTL. Third, the time needed to design and conduct SoTL is a scarce resource, given the current reward structure and the multiple commitments to research and teaching that shape faculty priorities in various ways. Finally, most faculty teaching in the disciplines are not trained in the principles of human learning and the research methodologies central to SoTL (Coppola \& Jacobs, 2002; Huber, 2002; Hutchings \& Shulman, 1999; Middendorf \& Pace, 2008; Wankat et al., 2002).

The ERG has not only fostered faculty participation in SoTL, but has also promoted a broader set of goals that faculty developers at all types of institutions have identified as priorities: "to create or sustain a culture of teaching excellence," "respond to and support individual faculty," "advance new initiatives in teaching and learning," and "foster collegiality" among faculty (Sorcinelli et al., 2006, p. 48). The ERG is a product of an approach to faculty development that prevails at our university and at many others, where teaching center staff, themselves faculty, approach their work as a collaboration with fellow faculty to develop programs and services that will enhance teaching and learning at the university (Sorcinelli et al., 2006).

\section{History of the ERG}

Faculty at our university often collaborate with colleagues to design and refine undergraduate courses in STEM. Such collaboration can include consultation with the teaching center director, who is also a professor of the practice in chemistry. Several years ago, a professor of biology began to work with the director to redesign a writing-intensive 
biology course, first during a teaching center workshop on teaching with writing, then in a series of consultations. The goal was to redesign her course's writing assignments and grading rubrics with a focus on determining whether students achieved the course learning objectives. Their conversations about this course led the professor and the director to think about new ways to apply this scholarly approach to teaching to the design and evaluation of a broad array of undergraduate STEM courses and programs supported by the university's multiyear grant from HHMI. Initially won in the early 1990s and continually renewed since then, the HHMI grant has been instrumental in the development of numerous initiatives in STEM education. As HHMI has increasingly emphasized the need to evaluate supported educational projects, the faculty involved in the HHMI courses and programs have become more interested in designing and conducting educational research.

In summer 2008, the biology professor met with the teaching center director and the science outreach director, also a member of the HHMI advisory panel, to discuss hiring a postdoctoral fellow to assist faculty with the design and execution of studies to evaluate the effectiveness of the HHMI-supported teaching innovations. During this discussion, they determined that what was needed was not just a single postdoctoral fellow but also a larger culture within which evaluation work could develop. To create such a culture, they decided to follow the model of a weekly laboratory research group meeting that would involve the newly hired postdoctoral fellow and faculty and staff involved in HHMI projects. This group, which they named the STEM ERG, would provide an opportunity for faculty and staff to learn how to develop effective evaluation plans for HHMI projects and would provide a venue for regular collegial discussions of teaching and learning-discussions that would ultimately improve teaching and learning across the university. The initial group consisted of faculty and staff involved in HHMI projects from the departments of biology, chemistry, mathematics, physics, science outreach, education, engineering, and the student learning center. In addition, the founders invited two faculty who were not involved in HHMI projects: a cognitive scientist and professor of psychology whose research is in learning and memory and an educational psychologist whose research is in collaborative learning. Recently the director of preservice programs in the department of education joined the group. The ERG has met every fall and spring semester since fall 2008. Approximately twentysix individuals have participated, with a group of thirteen core members participating on a regular basis during the nearly two and a half years since its inception. 


\section{Structure of ERG Meetings}

The group's weekly sessions function like laboratory research group meetings in the sciences. Each week, a group member gives a presentation on an ongoing project, which in some cases is the result of collaboration among multiple ERG members. This project is typically at one of three stages: an initial planning stage, involving the definition of the project's informing principles and objectives; a later planning stage, involving the development of evaluation methods; or a data analysis and conclusions stage. The projects range from the design and evaluation of instructional methods to the development of interdisciplinary research on learning approaches that students bring to first-year courses. The schedule of presentations for each semester is established at the end of the previous semester. Each member volunteers to present approximately once a year. The presenter may ask the group to read an article or two prior to the meeting or may use visuals, a handout, or an activity to structure the presentation and discussion during the meeting. Each presentation is brief, serving as a springboard for the discussion, the heart of each meeting. The discussion is lively and interactive, often including complex questions and vigorous debate about the project and appropriate evaluation methods. The ERG members are quick to challenge one another to develop methods and approaches that are understandable and applicable across disciplinary boundaries.

\section{ERG Member Perspectives}

To better understand the experiences of the STEM ERG members, one of us conducted interviews with all three ERG founders and with another core ERG member. The purpose of these interviews was to give these four individuals an opportunity to reflect on the group's objectives and benefits.

\section{Shared Benefits}

The ERG members report that they find great value in the energetic, collegial environment of the weekly meetings. They describe this environment as "friendly" and "open," as well as "engaging" and "challenging." One notes that the success of the meeting format is due in part to the fact that the majority of the ERG members are in disciplines in which the laboratory group meeting is a familiar model for scholarly conversation and collaboration. The ERG members are accustomed to and appreciate the scholarly give-and-take that occurs during each meeting, and they 
each take seriously their responsibilities to offer thoughtful feedback and questions that will help one another refine their respective projects. The ERG members agree that the cohesiveness of the group is a result of a shared sense of purpose: all participants are dedicated to, and excited about, advancing teaching and learning in STEM and improving the various types of educational research in which they are each engaged.

The ERG members value the diversity of the group. Participants bring different levels of expertise in SoTL and in research on learning. Some are just beginning to explore SoTL, and others have been conducting SoTL and science education research for many years. They also bring different perspectives on how to ask and answer questions about teaching and learning. For example, STEM faculty often approach these meetings with questions such as, "What methods or approaches can I use to help my students learn?" They focus on the learning objectives that shape their courses and on what they have learned about student learning, whether through observation or formal evaluation. Faculty who conduct research in cognitive and learning sciences bring questions such as, "What do you mean by learning?" and, "How can you measure learning?" They bring to the ERG knowledge about principles of human learning that have been identified not in classrooms but in laboratory research.

Initial group meetings quickly revealed that ERG members used different vocabularies to discuss teaching and learning. Subsequent meetings provided opportunities for the group to learn to lower the linguistic barriers that often separate faculty in STEM departments from those in social science departments and to develop ways of speaking to one another across these barriers. The conversation that occurs each week thus exemplifies the way in which multidisciplinary discussions about SoTL can establish a teaching commons-a space in which scholars from different disciplines can discuss and learn about teaching. As Huber and Hutchings (2005) describe it, the teaching commons is valuable because of its heterogeneity: "its vibrancy, like that of a city's, lies in the number, variety, and distinctiveness of its neighborhoods" (p. 71). The ERG members describe the multidisciplinary nature of the group as crucial to its value. One notes, for example, that the group offers a rare opportunity to "interact in a very scholarly and productive way with people who are in different disciplines." Participation in the ERG provides a means for members to critically examine their own disciplinary approaches and assumptions, learn about scholarship that they would not have otherwise known about, and develop valued collegial relationships across disciplines. 


\section{A Broader Perspective on Course Design and Evaluation}

The professor of biology brings to the ERG expertise in developing and teaching upper-division, writing-intensive courses in the sciences. As the principal investigator on the HHMI grant and chairperson of the biology department, she brings to the group expert knowledge about university-wide and national efforts to improve undergraduate STEM education. Her presentations to the group have focused on the redesign and evaluation of her writing-intensive course. Feedback from the group at the initial stage helped this professor and her co-instructor (also an ERG member) identify ways to measure whether the course is successful at helping students develop specific cognitive and writing skills, such as formulating ideas based on evidence and explaining concepts with the context that readers require. Once the co-instructors had developed an evaluation plan, they presented this plan to the ERG and again gathered feedback. Now that the evaluation phase is under way, they plan to return to the ERG with a subsequent presentation on the results of the evaluation.

The biology professor has appreciated the group's feedback and suggestions at each stage of her project. In fact, she finds that giving multiple presentations on her project has been productive rather than repetitive; each time she discusses new developments and questions with colleagues who are familiar with the project. The sequence of presentations, she notes, allows her to make progress on the project and to "progress in [her] thinking" about the project. She points out that the laboratory group structure of the ERG allows her to learn about other projects at a deeper level than she would at a research symposium. Moreover, learning about these projects at various stages of their development has given her a broader, enriched understanding of how colleagues in other disciplines think about teaching, student learning, and the process of evaluation.

\section{A K-20 Perspective on STEM Education}

The director of science outreach is an experienced educator who is working on a doctorate in science education. She has presented to the ERG on several projects, including a challenging project to evaluate the university's master's program for high school biology teachers. In this program, teachers take intensive summer courses and then design curricula based on the content taught in those courses. The rich conversation that has resulted from her presentations has helped her develop more robust approaches to collecting and analyzing data. More broadly, the 
weekly conversations with faculty who teach in STEM in higher education have informed her work helping high school teachers learn how to prepare their students for university-level work. By the same token, her knowledge of high school curricula and of the challenges that high school science teachers face is valuable to the ERG's STEM faculty, who are working to develop curricula and programs that help students make a successful transition to university courses. The science outreach director refers to this exchange of information as producing a $\mathrm{K}-20$ perspective on STEM education, and she sees it as one of the chief benefits of the ERG. She also notes that participating in the ERG has helped to raise awareness, within and beyond the group, that science outreach researchers and educators are engaged in scholarship that is integral to the university's mission. This awareness has helped to combat a common, reductive image of science outreach as developing programs that are merely "fun" and "supplemental," rather than integrated with the university's focus on research and postsecondary education.

\section{Collaborative Research on Teaching and Learning}

The teaching center director, a professor of the practice in chemistry, brings to the group expertise in effective teaching practices in STEM and in chemical education. Her approach to the latter field is unusual: she is a chemist who entered educational research as a faculty member teaching in the discipline rather than through doctoral work in science education. She has presented to the ERG on several topics, including her research on peer-led team learning and a first-year transition program in chemistry. Participating in the ERG has helped her develop research methods that approximate the methodologies that ERG colleagues in the social sciences use. At the same time, she notes that the participating STEM faculty have helped their social science colleagues understand the extent to which classic experimental methods cannot be applied rigidly in SoTL; instead they must be adapted to fit classroom teaching, where there are many variables and no true controls (Nummedal, Benson, \& Chew, 2002).

Another result of the director's participation in the ERG is the development of a collaborative project. The genesis of this project was a presentation to the ERG by a psychology professor whose research investigates how principles of cognitive science may be applied to improve instruction in the classroom. The presentation focused on a function learning test that the psychologist developed to identify two approaches that students take to learning: an algorithmic (rote learning) approach and a conceptual (theory-based) approach. This presentation 
sparked the interest of the teaching center director, who pointed out that these two approaches seemed to describe the two groups of students she has observed during many years of teaching general chemistry. These two ERG members developed a new project in which they are using the function learning test to identify the learning approaches of first-year students in the fall general chemistry course. Preliminary data show performance differences associated with these two approaches; later phases of the project will focus on developing interventions to benefit the lowerperforming group.

The collaboration between these two ERG members exemplifies the benefits of the group's multidisciplinary conversations on teaching and learning. Conversations among ERG members helped the psychologist become better informed about how STEM instructional environments differ from the more controlled laboratory environments where cognitive science research is conducted, and presented cognitive science research in ways that make its relevance more clear to STEM faculty. The chemist learned to use tools from cognitive science research to provide insights into student learning in a first-year course that is a part of the core undergraduate curriculum.

\section{Additional Collaborative Projects}

Faculty participation in the STEM ERG has spurred the development of other collaborative projects, including a redesign of objectives and assessments in a microbiology course, a study of student performance and satisfaction in general physics courses that replace the traditional lecture format with mini-lectures and group problem solving, and the development of a new approach to data analysis in a project evaluating the discourse in peer-led team learning groups.

\section{Next Steps}

The format of the ERG is evolving. The weekly meetings now focus less on presentation of information and more on formal planning of HHMI projects. Starting in spring 2011, most of the meetings are conducted in a working group format, in which members discuss each project and work together to develop clear objectives, evaluation methods, and a time line. The product of each meeting is intended to be a plan that the project manager can use to advance the project. This format will be especially valuable for new ERG collaborations, such as a planned project applying tools and insights from cognitive science to evaluate three 
different approaches to inquiry-based learning in upper-division science laboratory courses.

The success of the STEM ERG in its first phase has laid the groundwork for institutional support of SoTL across disciplines. Three ERG members have successfully lobbied the provost for the creation of a university center, to be funded starting in fall 2011, that will bring together the expertise of cognitive scientists and faculty teaching in the disciplines to produce research on teaching and learning. The provost's support will allow the hiring of a full-time staff scientist who will design and conduct evaluative studies for educational projects that are not funded by external grants and assist faculty in writing proposals to seek external support for SoTL.

\section{Advice on Starting an ERG}

While the ERG model uses a structure that is most familiar to faculty who conduct laboratory research, this model can foster the development of scholarship of teaching and learning in any discipline. In addition, it can be successful in a variety of settings, and not only at private, research-intensive, doctorate-granting universities. We offer the following advice to faculty developers who are interested in establishing an ERG:

- Leadership and knowledge of effective pedagogy are crucial to establishing and maintaining the group's focus on classroombased, discipline-specific issues. However, it is essential to develop and define the ERG in collaboration with one or two faculty colleagues and, when relevant, with leaders from educational outreach or student learning centers.

- Work with colleagues to define the group around a common purpose. Whether the purpose is to advance educational projects supported by a single grant or to investigate pedagogical objectives such as improving students' writing or problem-solving skills, this common purpose will help the ERG cohere and endure.

- Invite faculty and research staff from multiple departments and disciplines, and with different levels of expertise in SoTL, to participate. The different perspectives each brings to the group will create opportunities for the ERG members to think critically about the assumptions behind their respective disciplinary approaches and develop new insights that will improve their projects.

- When inviting faculty to participate, suggest how participation in SoTL can shed light on the teaching methods that they use in 
their own classes, as well as provide an opportunity to contribute to knowledge that can have an impact on teaching and learning beyond their own classrooms (Hutchings \& Shulman, 1999). It may be helpful to explain that the collaborative work of the group could take different forms, ranging from a collegial exchange of ideas on teaching, learning, and evaluation to the development of collaborative research projects.

- Play an active role in helping faculty learn how to communicate and share ideas across disciplinary boundaries. Think about the communication and knowledge gaps that might be stumbling blocks within the group. You can help bridge these gaps by drawing on your own expertise to suggest, for example, how research on learning can be applied to the development of specific, practical teaching methods.

- Develop a structure of regular, weekly meetings and schedule topics for each meeting well in advance.

- Use faculty symposia, newsletters, and other means to inform nonparticipating faculty and upper-level administrators about the ERG and its contributions to SoTL and to improving teaching and learning.

- Develop a regular mechanism for the members to reflect on the group's progress, make any necessary changes in its purpose and structure, and explore options for broader institutional and external support to advance the group's SoTL projects.

\section{Conclusion}

At our university, the STEM ERG has helped to bridge communication and knowledge gaps among STEM faculty, science education specialists, and faculty who conduct laboratory research in cognitive and learning sciences. The group has advanced existing HHMI-funded educational projects and prompted the development of collaborative, multidisciplinary projects that will shed light on specific questions about teaching and learning in STEM. Moreover, during its first two and a half years, the ERG has broadened the definition of scholarship at the university and has raised awareness among the faculty and administration about how faculty, the director of the teaching center, and researchers in science outreach and education are conducting scholarship that advances the university's mission of excellence in both teaching and research. 


\section{REFERENCES}

Banchoff, T., \& Salem, A. (2002). Bridging the divide: Research versus practice in current mathematics teaching and learning. In M. T. Huber \& S. P. Morreale (Eds.), Disciplinary styles in the scholarship of teaching and learning: Exploring the common ground (pp. 181-196). Sterling, VA: Stylus.

Boyer, E. L. (1990). Scholarship reconsidered: Priorities of the professoriate. San Francisco, CA: Jossey-Bass.

Coppola, B. P., \& Jacobs, D. C. (2002). Is the scholarship of teaching and learning new to chemistry? In M. T. Huber \& S. P. Morreale (Eds.), Disciplinary styles in the scholarship of teaching and learning: Exploring the common ground (pp. 197-216). Sterling, VA: Stylus.

Huber, M. T. (2002). Disciplinary styles in the scholarship of teaching: Reflections on the Carnegie Academy for the Scholarship of Teaching and Learning (orienting essay). In M. T. Huber \& S. P. Morreale (Eds.), Disciplinary styles in the scholarship of teaching and learning: Exploring the common ground (pp. 25-43). Sterling, VA: Stylus.

Huber, M. T., \& Hutchings, P. (2005). The advancement of learning: Building the teaching commons. San Francisco, CA: Jossey-Bass.

Huber, M. T., \& Morreale, S. P. (2002). Situating the scholarship of teaching and learning: A cross-disciplinary conversation. In M. T. Huber \& S. P. Morreale (Eds.), Disciplinary styles in the scholarship of teaching and learning: Exploring the common ground (pp. 1-24). Sterling, VA: Stylus.

Hutchings, P., \& Shulman, L. S. (1999, September/October). The scholarship of teaching: New elaborations, new developments. Change, 31(5), 10-15.

Middendorf, J., \& Pace, D. (2008). Easing entry into the scholarship of teaching and learning through focused assessment: The "decoding the disciplines" approach. In D. R. Robertson \& L. B. Nilson (Eds.), To improve the academy: Vol. 26. Resources for faculty, instructional, and organizational development (pp. 53-67). San Francisco, CA: Jossey-Bass.

Nummedal, S. G., Benson, J. B., \& Chew, S. L. (2002). Disciplinary styles in the scholarship of teaching and learning: A view from psychology. In M. T. Huber \& S. P. Morreale (Eds.), Disciplinary styles in the scholarship of teaching and learning: Exploring the common ground (pp. 163-179). Sterling, VA: Stylus.

Shulman, L. S. (1993, November/December). Teaching as community property: Putting an end to pedagogical solitude. Change, 25(6), 6-7. 
Sorcinelli, M. D., Austin, A. E., Eddy, P. L., \& Beach, A. L. (2006). Creating the future of faculty development: Leaming from the past, understanding the present. San Francisco, CA: Jossey-Bass.

Wankat, P. C., Felder, R. M., Smith, K. A., \& Oreovicz, F. S. (2002). The scholarship of teaching and learning in engineering. In M. T. Huber \& S. P. Morreale (Eds.), Disciplinary styles in the scholarship of teaching and learning: Exploring the common ground (pp. 217-237). Sterling, VA: Stylus. 